\title{
Purification and characterization of a novel lipopeptide from Streptomyces amritsarensis sp. nov. active against methicillin-resistant Staphylococcus aureus
}

\author{
Deepika Sharma', Santi M Mandal ${ }^{2}$ and Rajesh Kumari Manhas ${ }^{1^{*}}$
}

\begin{abstract}
Nowadays antimicrobial lipopeptides are being widely exploited for developing potential therapeutic agents for treating bacterial infections. In the present study, we have purified and characterized an antimicrobial lipopeptide produced by Streptomyces amritsarensis sp. nov. (= MTCC $11845^{\top}=$ JCM $\left.19660^{\top}\right)$. The lipopeptide was purified using silica gel chromatography, size exclusion chromatography and reverse phase- HPLC. The MS/MS analysis of the lipopeptide revealed that it has amino acid sequence as Ala-Thr-Gly-Ser-His-Gln and a long chain fatty acid tail with six times repeated the molecular mass of $161 \mathrm{Da}$ which is corresponding to $-\mathrm{C}_{12} \mathrm{H}_{1}$. Based on the molecular mass (878.5 Da) and amino acid composition, the lipopeptide was identified as a novel lipopeptide. The MIC values of purified lipopeptide against Bacillus subtilis (MTCC 619), Staphylococcus epidermidis (MTCC 435), Mycobacterium smegmatis (MTCC 6) and clinical strain, Methicillin Resistant Staphylococcus aureus (MRSA) were found to be 10, 15, 25 and $45 \mu \mathrm{g} / \mathrm{ml}$, respectively. It was completely stable at $70^{\circ} \mathrm{C}$ for $1 \mathrm{~h}$ and retained $81.8 \%$ activity after autoclaving $\left(121^{\circ} \mathrm{C}\right.$ for $\left.15 \mathrm{~min}\right)$. It did not show any change in its activity profile between pH $5.0-9.0$ and is stable to trypsin, proteinase $\mathrm{K}$ and lipase enzymes. It was found to be non-mutagenic against Salmonella typhimurium (TA98) and did not show cytotoxicity when checked against Chinese hamster ovary (CHO) cell line. In addition to antibacterial activity it also exhibits biosurfactant activity.
\end{abstract}

Keywords: Antibacterial; Novel; Lipopeptide; Thermostable; Non-toxic

\section{Introduction}

In the last two decades, exploring the possibility of developing new classes of antimicrobial compounds has emerged prominently due to pathogens acquired resistance to emerging antibiotics. Presently available antimicrobial compounds are getting old and less efficient, only few truly original replacements are available. This is due to a number of different reasons including daunting R\&D costs for putting a new molecule on a highly competitive market and the inherent difficulty of identifying innovative antibiotic targets (Nathan and Goldberg 2005; Payne et al. 2007). Therefore, screening and characterization of the novel antimicrobial compounds especially, peptides from

\footnotetext{
*Correspondence: rkmanhas@rediffmail.com

'Department of Microbiology, Guru Nanak Dev University, Amritsar, Punjab 143005, India

Full list of author information is available at the end of the article
}

microorganisms, have drawn attention (Pirri et al. 2009; Laverty et al. 2011). Among antimicrobial peptides, lipopeptides are small molecules and have been considered as potential source of future antibiotics because of their different mechanisms of action as compared to conventional antibiotics (Baindara et al. 2013).

Antimicrobial lipopeptides represent an old class of antibiotics that were discovered over 50 years ago and consist of a hydrophilic cyclic peptide portion attached to a fatty acid chain. They are biosynthesized by large multi-enzymes called non-ribosomal peptide synthetases via non-ribosomal pathways (Pirri et al. 2009). All antibiotics belonging to this novel class contain multiple nonproteinogenic amino acids as well as different lipid tails; this yields remarkable structural diversity (Strieker and Marahiel 2009). Lipopeptides easily bind to the bacterial surface bilayer and alter the local lipid organizational 
linking on negatively charged fatty acids resulting in restructuring of the lipid bilayer and prevent cellular processes (Horn et al. 2012; Mandal et al. 2013).

Actinobacteria especially, species of the genus Streptomyces are reported to produce diverse antimicrobial lipopeptides with their applications in pharmaceutical industries. Amphomycin was the first lipopeptide to be discovered from Actinoplanes friuliensis, followed by a number of related antibiotics, including crystallomycin, aspartocin, glumamycin, laspartomycin, tsushimycin, and the best studied so far, daptomycin (Schneider et al. 2009). As apparently 99\% of the microbial species are still unexplored (Davies 1999; Watve et al. 2001) therefore, possibility of discovering actinobacteria producing potent and novel lipopeptides still remains. In the light of this, present study was aimed at purification and characterization of a novel antimicrobial lipopeptide produced by Streptomyces amritsarensis.

\section{Materials and methods}

\section{Microorganism and maintenance}

Streptomyces amritsarensis $\left(=\right.$ MTCC $11845^{\mathrm{T}}=\mathrm{JCM}$ $19660^{\mathrm{T}}$ ) was isolated from soil and identified using polyphasic taxonomic approach (Sharma et al. 2014). The culture was maintained on starch casein nitrate agar slopes at $4{ }^{\circ} \mathrm{C}$ and as mycelial fragments and spores in $20 \% \mathrm{v} / \mathrm{v}$ glycerol at $-80^{\circ} \mathrm{C}$. All the test organisms except clinical isolates were procured from Microbial Type Culture Collection and Gene Bank (MTCC), Institute of Microbial Technology (IMTECH), Chandigarh, India. Clinical isolates viz. multi-drug resistant $E$. coli, MRSA and VRE were procured from local hospitals. They were maintained on nutrient agar slopes at $4^{\circ} \mathrm{C}$.

\section{Growth and lipopeptide production profile}

$S$. amritsarensis was grown in Starch Casein Nitrate (SCN) broth at $28^{\circ} \mathrm{C}$ with continuous shaking at $180 \mathrm{rpm}$ for 10 days. Cell free supernatants were collected at one day intervals by centrifuging culture broths at 10,000 rpm for $30 \mathrm{~min}$ at $4^{\circ} \mathrm{C}$ and used for detection of lipopeptide antimicrobial activity using Kirby-Bauer disk diffusion susceptibility test (Bauer et al. 1966). Filter paper discs $(6 \mathrm{~mm})$ impregnated with $10 \mu \mathrm{l}$ of supernatants (filtered through $0.22 \mu \mathrm{m}$ filter, Pall Lifesciences) were placed on Mueller-Hinton agar plate seeded with Bacillus subtilis (MTCC 619) and incubated at $37^{\circ} \mathrm{C}$ for $24 \mathrm{~h}$. For the determination of growth, absorbance of culture broths were read at $600 \mathrm{~nm}$ and growth curve was prepared. Protein contents of culture supernatants were determined using Lowry method (Lowry et al. 1951).

For large scale production of lipopeptide batch fermentation of Streptomyces strain was carried out in SCN broth at $28^{\circ} \mathrm{C}$ on a rotary shaker at $180 \mathrm{rpm}$. The flasks were inoculated with $2 \%$ by volume of seed culture, grown at $28^{\circ} \mathrm{C}$ for two days. Fermentation was terminated on $4^{\text {th }}$ day, at which the maximum production was obtained. The active compound from cell free supernatant was adsorbed on resin XAD-4 (5\%) at $15^{\circ} \mathrm{C}$ under shaking conditions for 2 days and recovered from resin by eluting with methanol. The methanol fraction was dried using a rotavapour (BUCHI Rota vapor R-200) and dried residue was re-dissolved in small volume of methanol.

\section{Purification of lipopeptide}

For the purification of the lipopeptide silica gel column chromatography (60-120 mesh) was carried out. Column $(35 \times 1.0 \mathrm{~cm})$ was packed with silica gel using chloroform as solvent. The methanol extract was loaded at the top of the column and eluted step-wise with $100 \% \mathrm{CHCl}_{3}$, 95:5, 90:10, 75:25, 70:30, 50:50 (v/v) of $\mathrm{CHCl}_{3}: \mathrm{CH}_{3} \mathrm{OH}$ solvent and $100 \% \mathrm{CH}_{3} \mathrm{OH}(200 \mathrm{ml}$ each) at a flow rate of $2 \mathrm{ml} / \mathrm{min}$. Fractions were concentrated and redissolved in the same solvent ratio from which they were recovered. Fractions showing antimicrobial activity were pooled and further purified by subjecting to size exclusion chromatography using Toyopearl resin HW-40 and methanol as an eluent. The methanol fractions as such were subjected to antimicrobial activity, active fractions were combined and solvent was evaporated using a rota vapour, the residue was re-dissolved in Milli- $Q$ water. Further purification was achieved through reverse phase HPLC (1260 Infinity, Agilent Technologies, USA) using a semi-preparative C18 column (Pursuit 10C18 250x $21.2 \mathrm{~mm}$ ) and acetonitrile: water (5:5) as mobile phase. Collected fractions were concentrated by speed vacuum and screened for antimicrobial activity. Lipopeptide was purified to homogeneity using reverse phase- HPLC (Agilent 1100 series) with a ZORBAX 300-SB18 column $(4.6 \mathrm{~mm} \times 250 \mathrm{~mm}$, particle size $5 \mu \mathrm{m})$, at a flow rate of $1 \mathrm{ml} / \mathrm{min}$. The solvent system used was $0.1 \%$ aqueous TFA (A) and acetonitrile containing 0.1\% TFA (B). The gradient of solvent $\mathrm{B}$ used to run the column was as follows: $0-60 \%$ for $0-45 \mathrm{~min}, 60-80 \%$ for $45-55 \mathrm{~min}$ and $80-100 \%$ for $55-60 \mathrm{~min}$. The elution from the column was monitored at $215 \mathrm{~nm}$ in a diode array detector and all the peaks of HPLC chromatogram were collected using a fraction collector (GILSON, France) coupled with the system. Collected fractions were concentrated by speed vacuum and screened for antimicrobial activity.

\section{MALDI-TOF-MS and sequencing of lipopeptide}

Lipopeptide was characterized using Matrix-assisted laser desorption ionization (MALDI). The purified lipopeptide was lyophilized and re-suspended in methanol. Solution $(4 \mu \mathrm{l})$ was mixed with $4 \mu \mathrm{l}$ of matrix (CHCA, $10 \mathrm{mg} / \mathrm{ml}), 1.0 \mu \mathrm{l}$ of this mixture solution was spotted onto the MALDI 100 well stainless steel sample plate and allowed to air dry prior to the MALDI analysis 
(Mandal et al. 2009). MALDI mass spectra was obtained using a Voyager time-of-flight mass spectrometer (Applied Biosystem, USA), equipped with $337 \mathrm{~nm} \mathrm{~N} 2$ laser and operated in accelerating voltage $20 \mathrm{kV}$. The spectra were recorded in positive ion linear mode. To check the reproducibility of the spectrum, sample was separately spotted several times.

For peptide MS/MS sequencing, lipopeptide was incubated with $10 \% \mathrm{NaOH}$ in methanol at room temperature for $16 \mathrm{~h}$ to cleave the lactone ring. The cleaved lipopeptide was lyophilized, again extracted with methanol and allowed for mass spectrometry analysis. The spectra were recorded in the post-source decay (PSD) ion mode as an average of 100 laser shots with a grid voltage of $75 \%$. The reflector voltage was reduced in $25 \%$ steps and guide wire was reduced $0.02-0.01 \%$ with an extraction delay time of $100 \mathrm{~ns}$.

\section{Fatty acid analysis of lipopeptide by GC-MS}

Lipopeptide was subjected to acid hydrolysis by incubating the lipopeptide $\left(5 \mathrm{mg}\right.$ ) with $0.5 \mathrm{ml}$ of $6 \mathrm{M} \mathrm{HCl}$ at $90^{\circ} \mathrm{C}$ for $18 \mathrm{~h}$ in sealed tubes. The fatty acids were extracted with ether and esterified with $0.95 \mathrm{ml}$ methanol and $0.05 \mathrm{ml}$ of $98 \% \mathrm{H}_{2} \mathrm{SO}_{4}$ at $65^{\circ} \mathrm{C}$ for $6 \mathrm{~h}$. Fatty acid methyl esters were obtained after extraction with $\mathrm{n}$-hexane and analyzed by GC-MS with a Clarus 500 GC (PerkinElmer, USA). Helium was used as carrier gas at a flow rate of $1.0 \mathrm{ml} / \mathrm{min}$. The column temperature was maintained at $120^{\circ} \mathrm{C}$ for $3 \mathrm{~min}$ and thereafter gradually increased $\left(8^{\circ} \mathrm{C} / \mathrm{min}\right)$ to $260^{\circ} \mathrm{C}$.

\section{Determination of antimicrobial activity}

Sensitivity of test organisms to purified lipopeptide was measured in terms of zone of inhibition using Kirby-Bauer disk diffusion susceptibility test (Bauer et al. 1966). The plates containing Mueller-Hinton agar, yeast malt agar and potato dextrose agar were seeded with test bacteria, yeasts and fungi, respectively. Filter paper discs $(6 \mathrm{~mm})$ impregnated with $10 \mu \mathrm{g}$ of lipopeptide were placed on media plates. The diameter of the resultant zone of inhibition was measured in $\mathrm{mm}$ after 24- 48 hours of incubation. Each experiment was performed in duplicates and repeated thrice. Various test organisms used in the study included Bacillus subtilis (MTCC 619), Mycobacterium smegmatis (MTCC 6), Staphylococcus epidermidis (MTCC 435), Escherichia coli (MTCC 1885), Klebsiella pneumoniae sub sp. pneumoniae (MTCC 109), Enterobacter aerogenes (MTCC 111), Salmonella typhi (MTCC 733), multi-drug resistant $E$. coli, MRSA, VRE, Candida albicans (MTCC 3017), Rhodotorula rubra (MTCC 248), Colletotrichum acutatum (MTCC 1037), Cercospora beticola (GenBank acc. no. KJ461435), Fusarium oxysporum f. sp. dianthi (MTCC 6659), and Alternaria brassicicola (MTCC 2102).

\section{Determination of minimum inhibitory concentration}

The MIC of purified lipopeptide was evaluated by using a microtiter plate dilution assay. Test bacteria were grown to logarithmic phase under optimal conditions (up to $0.3 \mathrm{OD}$ ) and the test was performed in triplicates. To each well of the microtiter plate, $200 \mu \mathrm{l}$ of fresh nutrient medium and $50 \mu \mathrm{l}$ of bacterial suspension were added. Subsequently, different dilutions $(50 \mu \mathrm{l})$ of freshly prepared samples were added to each well. The first column of the microtiter plate was left as a blank, containing fresh medium only. The microtiter plates were incubated at $37^{\circ} \mathrm{C}$ and $\mathrm{OD}$ was measured at $600 \mathrm{~nm}$ at 24 and $48 \mathrm{~h}$ using ELISA microplate reader (Bio-rad, Model 680XR). The lowest concentration that inhibited growth of the test strain and did not show any increase in absorption after $48 \mathrm{~h}$ was considered as MIC of the lipopeptide for that strain.

\section{Effect of $\mathrm{pH}$, temperature and enzymes on lipopeptide activity}

Sensitivity to temperature was determined by incubating the purified lipopeptide at different temperatures viz. $50^{\circ} \mathrm{C}, 60^{\circ} \mathrm{C}, 70^{\circ} \mathrm{C}, 80^{\circ} \mathrm{C}, 90^{\circ} \mathrm{C}, 100^{\circ} \mathrm{C}$ and $121^{\circ} \mathrm{C}$ for different durations. To determine the optimum $\mathrm{pH}$ for activity, purified compound was incubated over $\mathrm{pH}$ range of 3.0-12.0 for $30 \mathrm{~min}$ at $37^{\circ} \mathrm{C}$. The sensitivity of the lipopeptide $(1.0 \mathrm{mg} / \mathrm{ml})$ to enzymes was tested against proteinase $\mathrm{K}$ $(\sim 30 \mathrm{U} / \mathrm{mg})$, trypsin $(\sim 10,000 \mathrm{U} / \mathrm{mg})$ and lipase $(\sim 9 \mathrm{U} / \mathrm{mg})$. All enzymes were purchased from Sigma Aldrich. Enzyme solutions were prepared at $1.0 \mathrm{mg} / \mathrm{ml}$ in $50 \mathrm{mM}$ phosphate buffer ( $\mathrm{pH}$ 7.0). Equal volumes of enzyme solution and antimicrobial compound ( $20 \mu \mathrm{l}$ each) were mixed and incubated at $37^{\circ} \mathrm{C}$ for $12 \mathrm{~h}$. The enzyme reaction was terminated by heating reaction mixture at $80^{\circ} \mathrm{C}$ and residual activity was determined by disc diffusion method.

\section{Safety evaluation of lipopeptide}

Mutagenicity of the lipopeptide was evaluated by Ames test (Maron and Ames 1983). This Salmonella reverse mutation test is based on histidine dependence and mutations in Salmonella typhimurium (TA98/ MTCC 1251, IMTECH, Chandigarh). Concentrations of the lipopeptide used for checking toxicity were 50 and $100 \mu \mathrm{g}$ $0.1 \mathrm{ml}^{-1}$ plate $^{-1}$. The overnight grown, $0.1 \mathrm{ml}$ bacterial culture and $0.1 \mathrm{ml}$ of lipopeptide were added to $2.0 \mathrm{ml}$ of top agar. The contents were mixed and poured onto glucose minimal agar plates immediately. The plates were inoculated and incubated at $37^{\circ} \mathrm{C}$ for $48 \mathrm{~h}$. The experiment was repeated to confirm the results. To determine the spontaneous reversion which is characteristic of the tester strain (TA 98), negative control ( $0.1 \mathrm{ml}$ bacterial culture + 0.1 ml DMSO plate ${ }^{-1}$ ) was run while 4-Nitro-ophenylenediamine $\left(20 \mu \mathrm{g} 0.1 \mathrm{ml}^{-1}\right.$ plate $\left.^{-1}\right)$ was used as a positive control mutagen. The mutagenic potential of the 
lipopeptide was determined by comparing the number of colonies with control plates where no test compound was added.

In vitro cytotoxicity was evaluated using sulforhodamine B dye assay (Skehan et al. 1990). The Chinese hamster ovary cell line $(\mathrm{CHO})$ was used for the assay. Camptothecin (CPT), an anticancer drug was used as standard. The 96-well tissue culture plate, containing different concentrations of lipopeptide $(2.5-25 \mu \mathrm{g} / \mathrm{ml})$ and $\mathrm{CHO}$ cells, was incubated for $48 \mathrm{~h}$ and the cell growth was stopped with trichloroacetic acid (50\% TCA, $50 \mu \mathrm{l})$. The optical density (OD) was recorded at $540 \mathrm{~nm}$ on ELISA reader and percent growth inhibition was calculated.

\section{Biosurfactant property of lipopeptide}

Biosurfactant property of lipopeptide was determined using the qualitative drop-collapse test (Youssef et al. 2004). In this method, mineral oil $(2 \mu \mathrm{l})$ was added to 96-well microtitre plate. The plate was equilibrated for $1 \mathrm{~h}$ at $37^{\circ} \mathrm{C}$ and $5 \mu \mathrm{l}$ of the lipopeptide $(10 \mu \mathrm{g}$, dissolved in water) was added to the surface of the oil and drop shape was observed after $1 \mathrm{~min}$. The surface tension of a lipopeptide $(0.2 \%, \mathrm{w} / \mathrm{v})$ was measured using Du-NouyRing method (Du Noüy and Pierre 1925).

\section{Results}

\section{Production and purification of lipopeptide}

Lipopeptide production and growth profile of S. amritsarensis is shown in Figure 1. Antimicrobial activity appeared in culture supernatant during late logarithmic phase. A significant increase in production (as measured by inhibition zone) and growth were observed with further incubation. The maximum growth and production were attained after 4 days which remained constant for 7 days and declined slightly with further incubation.

For purification of compound, production was carried out in SCN broth for 4 days. The active compound from supernatant was adsorbed on resin XAD-4 and recovered by eluting with methanol. Antimicrobial compound was partially purified by silica gel chromatography and size exclusion chromatography using Toyopearl resin HW-40. Reverse phase- HPLC of the partially purified compound using a semi-preparative C18 column revealed the presence of five peaks (Additional file 1: Figure S1). After lyophilization, all collected peaks (fractions) were tested for antimicrobial activity. Peaks 1, 2 and 3, demonstrating antimicrobial activity, were further resolved using ZORBAX 300-SB18 column (Figure 2).

\section{Lipopeptide MS/MS sequencing}

The primary structure of lipopeptide (peak 3 ) was elucidated using a combination of mass spectrometry techniques. The peaks obtained for different fragments at $\mathrm{m} / \mathrm{z}$ 834, 736, 665, 564, 507, 420, 283 and 155 in MS/MS analysis revealed the lipopeptide sequence as Ala-Thr-Gly-SerHis-Gln. The C-terminal amino acid in peptide is linked to aliphatic chain of $-\left(\mathrm{CH}_{2}\right)_{7}-\mathrm{CH}_{2}-\left(\mathrm{CH}_{3}\right)_{2^{-}}$with a total mass value of $\mathrm{m} / \mathrm{z}$ 878.5 Da (Figure 3). Further, MALDI TOF MS analysis clearly showed an addition of $137 \mathrm{Da}$ mass unit corresponding to $-\mathrm{C}_{10} \mathrm{H}_{17}$ - shown in figure inset (Figure 4). Interestingly, there is a long tail of fatty acid chain with six times repeated the molecular mass of $161 \mathrm{Da}$ which is corresponding to $-\mathrm{C}_{12} \mathrm{H}_{19}$ (Figure 3). Based on the molecular mass and amino acid composition, the lipopeptide was identified as a novel lipopeptide.

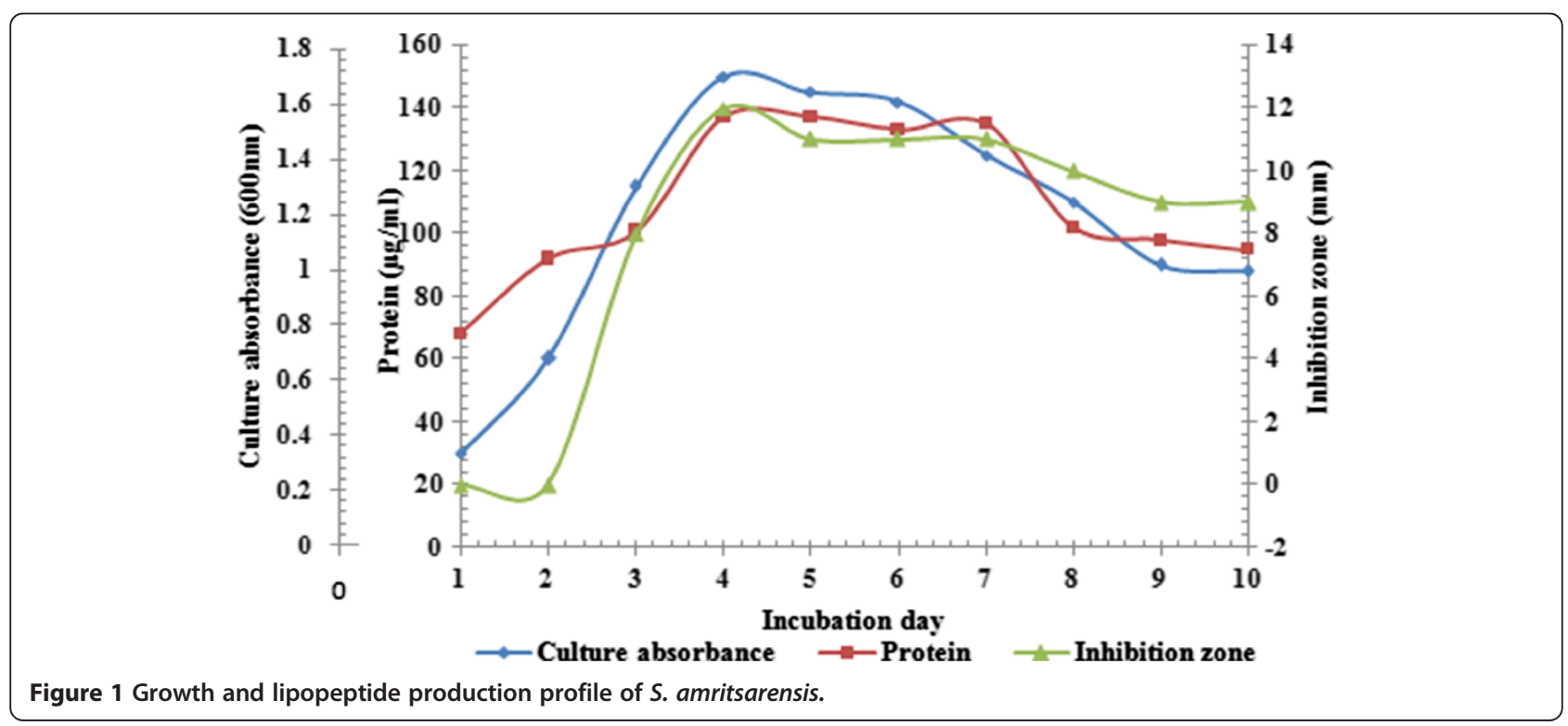




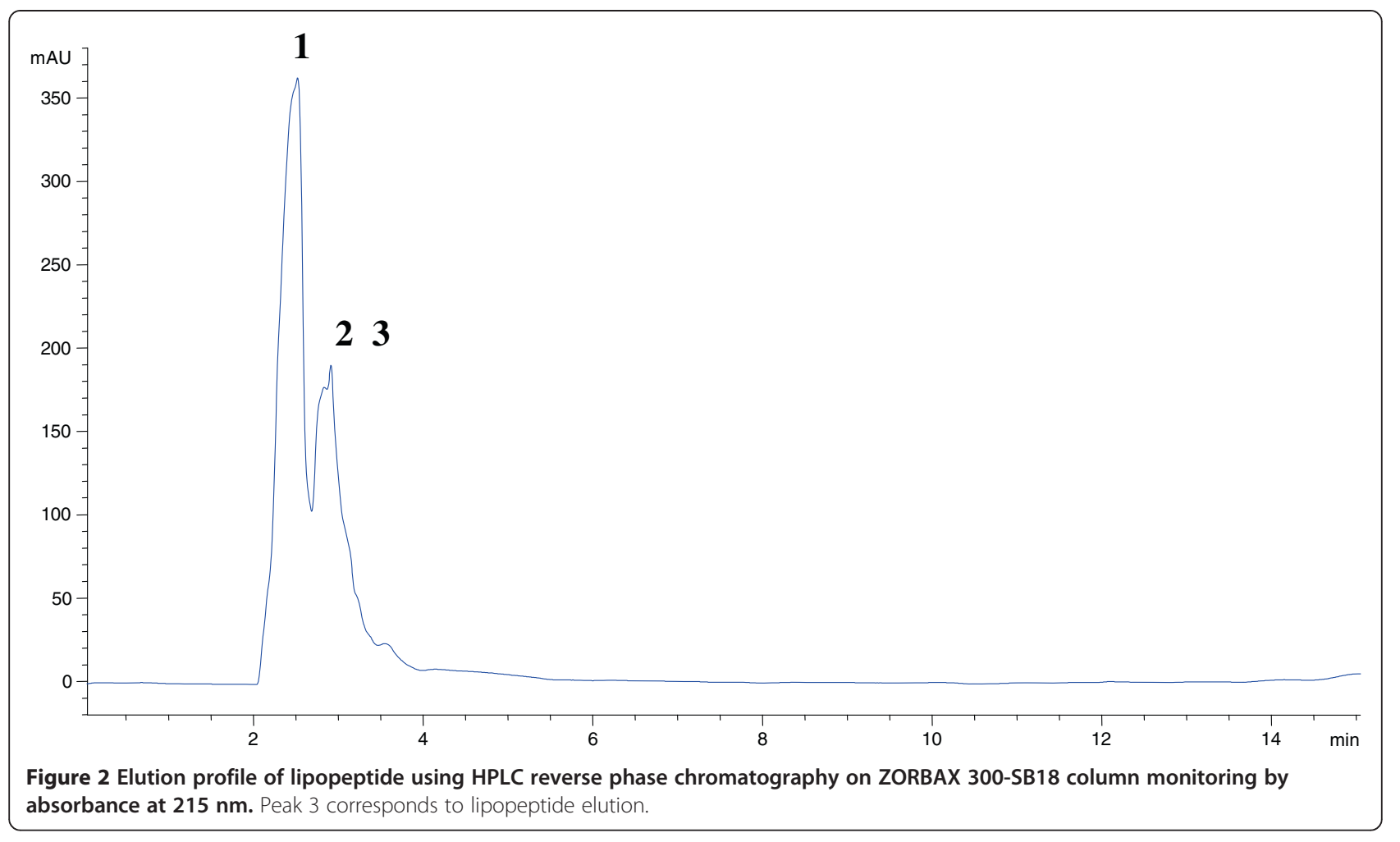

\section{Inhibition spectrum and sensitivity of the lipopeptide}

The purified lipopeptide $(10 \mu \mathrm{g})$ showed activity only against Gram positive bacteria with inhibition zones of 21, 17, 15 and $13 \mathrm{~mm}$ against B. subtilis, S. epidermidis, M. smegmatis and MRSA, respectively (Additional file 1: Figure S2). It did not show activity against any of the tested Gram-negative bacteria and fungi. The MIC assay for test organisms with purified lipopeptide using micro- titer plates in triplicates revealed lowest MIC value of $10 \mu \mathrm{g} / \mathrm{ml}$ against B. subtilis and highest against MRSA i.e $45 \mu \mathrm{g} / \mathrm{ml}$ (Figure 5).

The results of heat stability assay demonstrated that the lipopeptide was completely stable at $70^{\circ} \mathrm{C}$ for $1 \mathrm{~h}$ and a loss of $13.7 \%$ was observed at $100^{\circ} \mathrm{C}$ after 15 minutes incubation. After autoclaving $\left(121^{\circ} \mathrm{C}\right.$ for $\left.15 \mathrm{~min}\right)$ antimicrobial activity was reduced by $18.2 \%$. It did not show

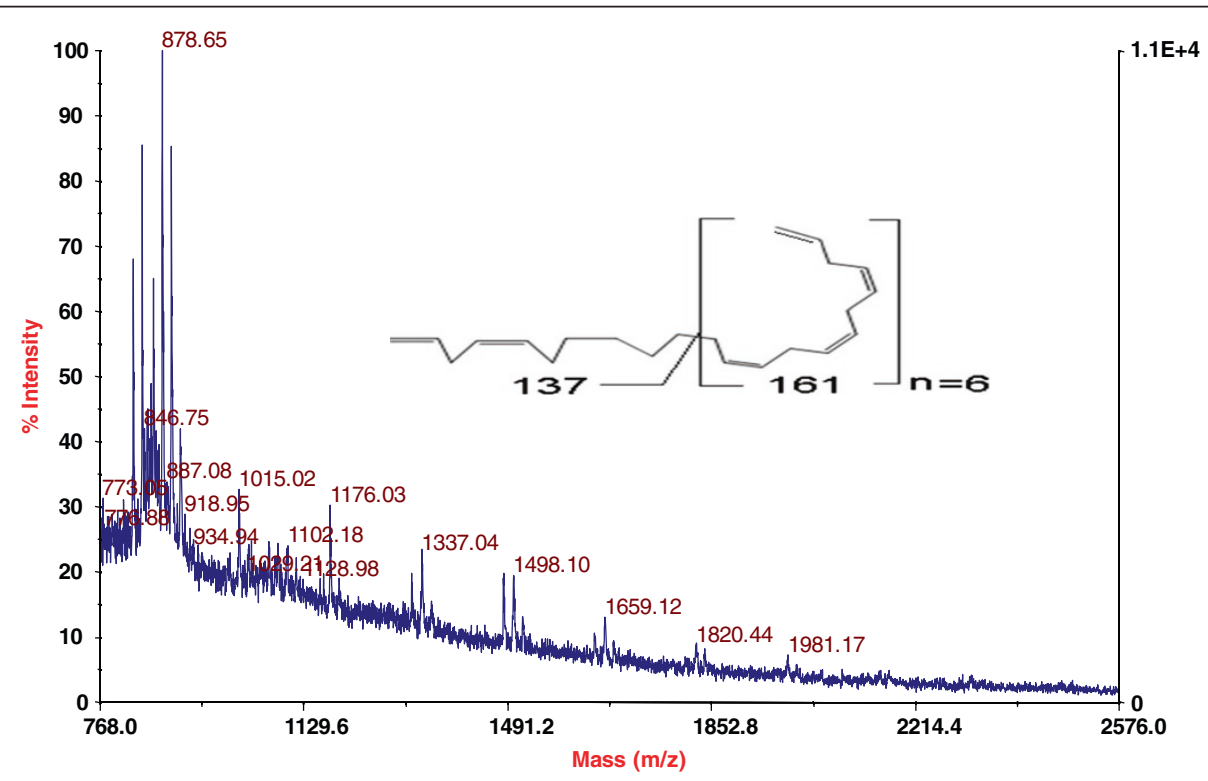

Figure 3 MALD-TOF mass spectrometry analysis of lipopeptide. 


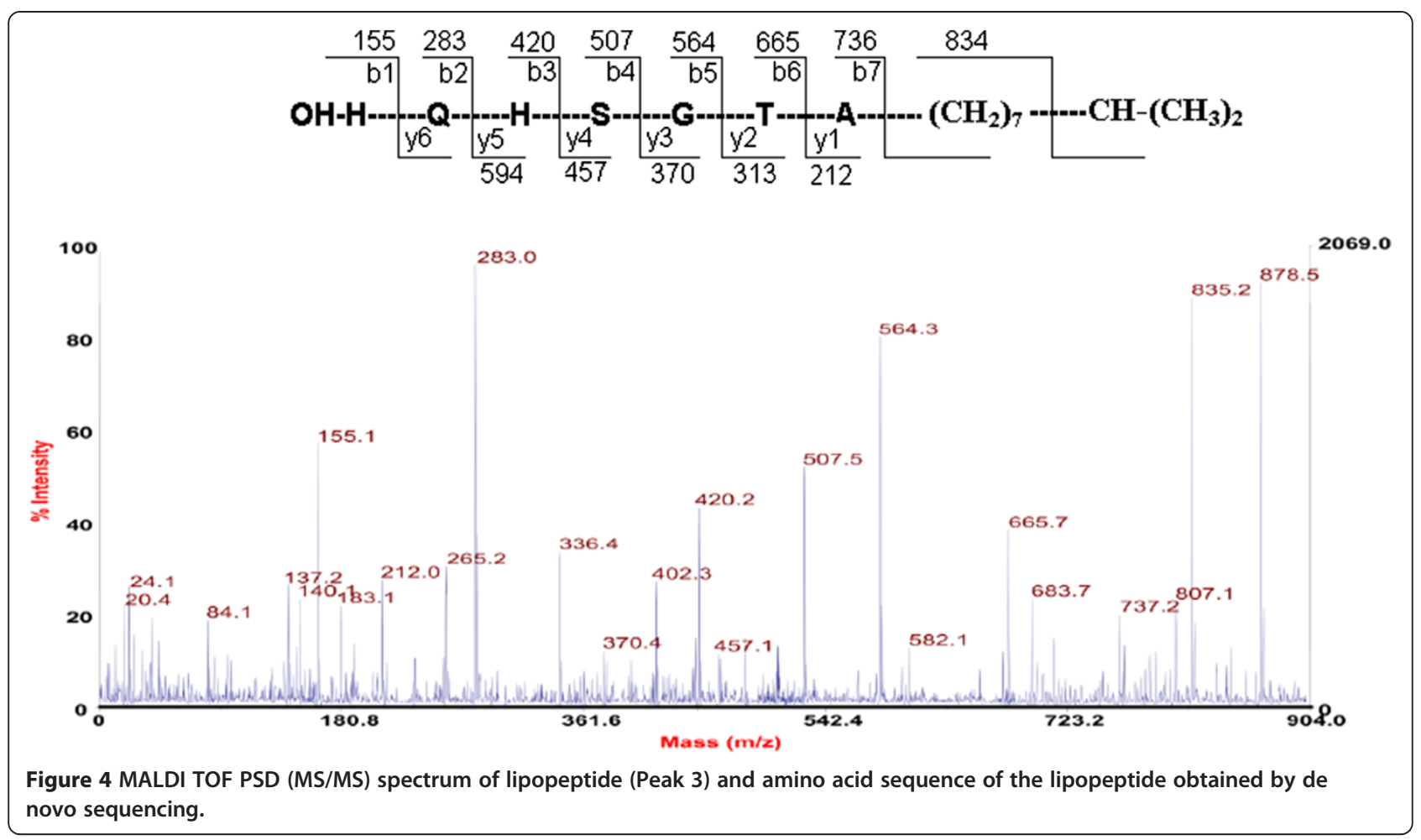

any change in its activity profile between $\mathrm{pH}$ 5.0-9.0 (Table 1). Lipopeptide was found to be resistant to trypsin and lipase, and negligible loss in activity was observed after treatment with proteinase $\mathrm{K}$.

\section{Safety evaluation}

Mutagenicity of lipopeptide was checked by Ames test at two concentrations viz. 50 and $100 \mu \mathrm{g} / 0.1 \mathrm{ml}$. The number of revertant colonies were counted after 48 hours of incubation at $37^{\circ} \mathrm{C}$ and compared with the negative control. The number of revertant colonies in the presence of lipopeptide was found to be same as in the negative control $(21 \pm 2.0)$ for TA98. However, the number of colonies in presence of positive mutagen $(20 \mu \mathrm{g}$ plate $^{-1}$ ) was found to be considerably higher. The results of the present study indicate that the lipiopeptide is non-mutagenic.

The effect of lipopeptide at different concentrations, $2.5-25 \mu \mathrm{g} / \mathrm{ml}$ on chinese hamster ovary $(\mathrm{CHO})$ cell line is shown in Figure 6. It showed 2.9, 16.8, 19.25, 23.28

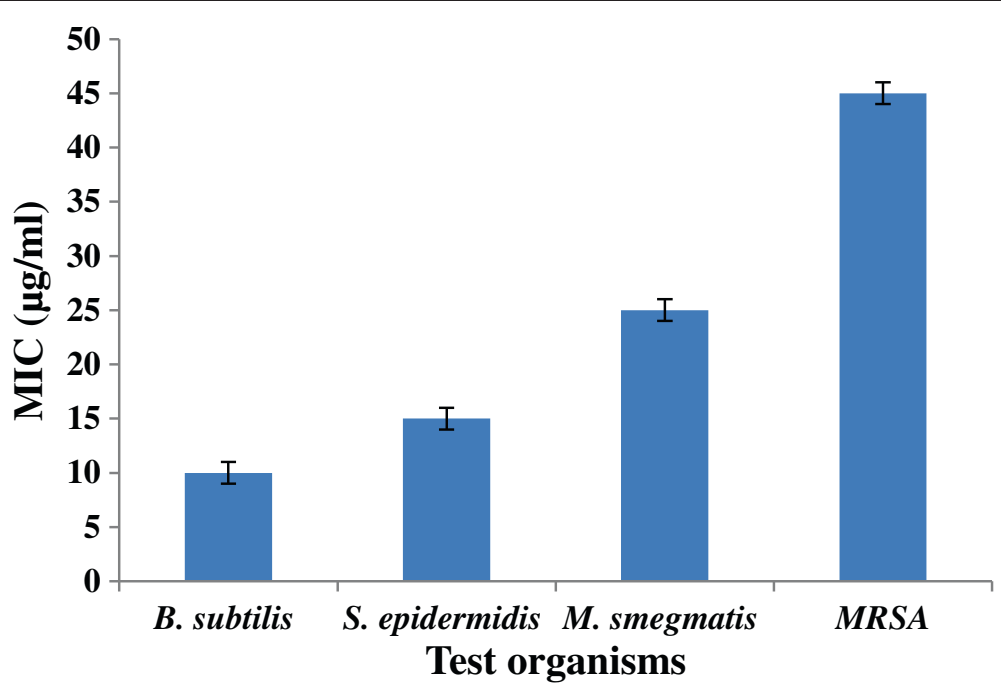

Figure 5 Determination of MIC for lipopeptide. 
Table 1 Factors affecting lipopeptide activity

\begin{tabular}{ccc}
\hline Treatment & $\begin{array}{c}\text { Reaction } \\
\text { duration/condition }\end{array}$ & $\begin{array}{c}\text { Residual activity } \\
\text { (\%) }\end{array}$ \\
\hline $\mathrm{pH}$ & $1 \mathrm{~h} / 4^{\circ} \mathrm{C}$ & 0 \\
2 & $1 \mathrm{~h} / 4^{\circ} \mathrm{C}$ & 72.7 \\
3 & $1 \mathrm{~h} / 4^{\circ} \mathrm{C}$ & 84.6 \\
4 & $1 \mathrm{~h} / 4^{\circ} \mathrm{C}$ & 100 \\
5 & $1 \mathrm{~h} / 4^{\circ} \mathrm{C}$ & 100 \\
6 & $1 \mathrm{~h} / 4^{\circ} \mathrm{C}$ & 100 \\
7 & $1 \mathrm{~h} / 4^{\circ} \mathrm{C}$ & 100 \\
8 & $1 \mathrm{~h} / 4^{\circ} \mathrm{C}$ & 100 \\
9 & $1 \mathrm{~h} / 4^{\circ} \mathrm{C}$ & 86.3 \\
10 & $1 \mathrm{~h} / 4^{\circ} \mathrm{C}$ & 68.1 \\
11 & $1 \mathrm{~h} / 4^{\circ} \mathrm{C}$ & 0 \\
12 & & 100 \\
\hline Temperature $\left({ }^{\circ} \mathrm{C}\right)$ & $1 \mathrm{~h}$ & 100 \\
50 & $1 \mathrm{~h}$ & 100 \\
60 & $1 \mathrm{~h}$ & 84.2 \\
70 & $1 \mathrm{~h}$ & 95.0 \\
80 & $15 \mathrm{~min}$ & 86.3 \\
90 & $15 \mathrm{~min}$ & $\mathrm{~min}(304 \mathrm{KPa})$ \\
100 & & \\
\hline
\end{tabular}

and $28.9 \%$ growth inhibition at concentrations of 2.5 , $6.25,12.5,18.75$ and $25 \mu \mathrm{g} / \mathrm{ml}$, respectively. The $\mathrm{IC}_{50}$ value of lipopeptide was found to be $387 \mu \mathrm{g} / \mathrm{ml}$ which is very high as compared to the $\mathrm{IC}_{50}$ value of standard drug $(0.959 \mu \mathrm{g} / \mathrm{ml})$. The cytotoxicity \% inhibition of standard (camptothecin) is shown in Figure 7. This indicates that it do not exhibit cytotoxicity.

\section{Lipopeptide as biosurfactant}

The lipopeptide collapsed the oil drop and lowered surface tension of water from 72 to $37 \mathrm{mN} \mathrm{m}^{-1}$ when used at a concentration of $0.2 \%$. These results show that it possesses good surfactant activity.

\section{Discussion}

Due to few antibiotics and free availability of effective antibiotics against diverse bacterial species the antimicrobial era is threatened by high levels of antibiotic resistance (Song 2008). Among infections caused by antibiotic resistant Gram-positive bacteria, MRSA and VRE are of particular concern (Rice 2008) and this lead to the discovery of potential antibiotics such as vancomycin, teicoplanin, synercid (quinipristin and dalfopristin), tigecycline and linezolid. Daptomycin is the recent FDA-approved lipopeptide, exhibiting potent activity against a broad range of Gram-positive pathogens especially, MRSA and VRE. However, rare incidences of clinical resistance have also been reported against daptomycin (D'Costa et al. 2012). Since resistance to each new antibiotic ultimately emerges, usually within few years after it is marketed, there is always a need to find new antimicrobial agents to combat antibiotic resistant strains of pathogenic and opportunistic pathogenic microorganisms.

Since the late 1960s, only two novel classes of antibiotics, the oxazolidinones and the cyclic lipopeptides, have entered the market (Rodriguez de Castro et al. 2009). Thus antibiotic market is looking to increase the number of new products with improved effectiveness. Nowadays, a huge amount of resources is being invested in R\&D to find novel antimicrobials that can solve the problem of antibiotic resistance (Maria-Neto et al. 2012). The market for antibacterial drugs is highly competitive, and many companies are engaged in the development of anti-MRSA or

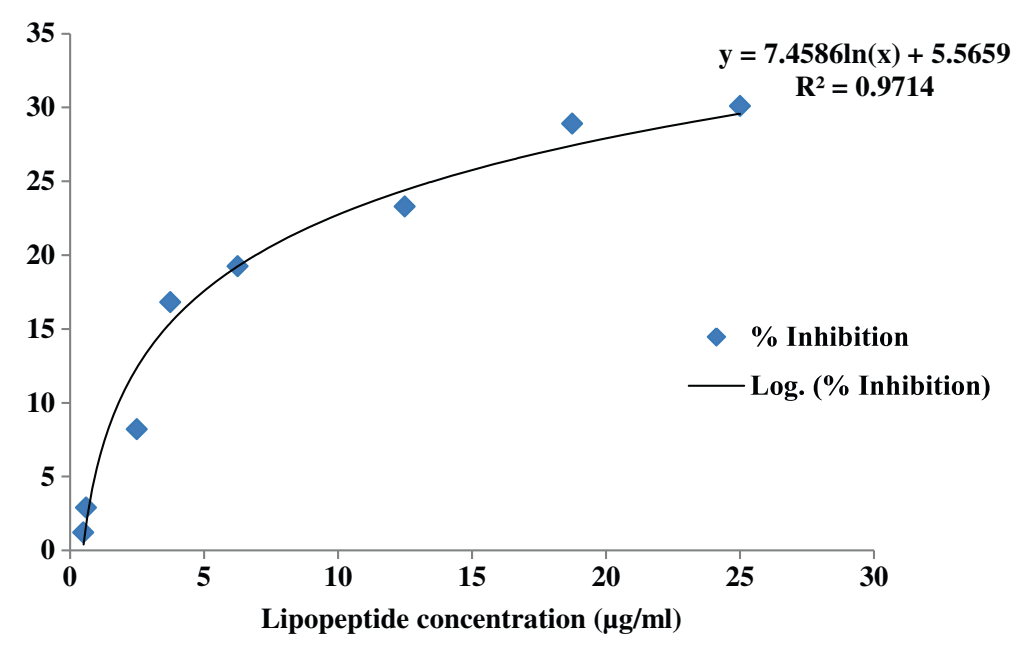

Figure 6 Cytotoxic effect of lipopeptide on CHO cell line. 


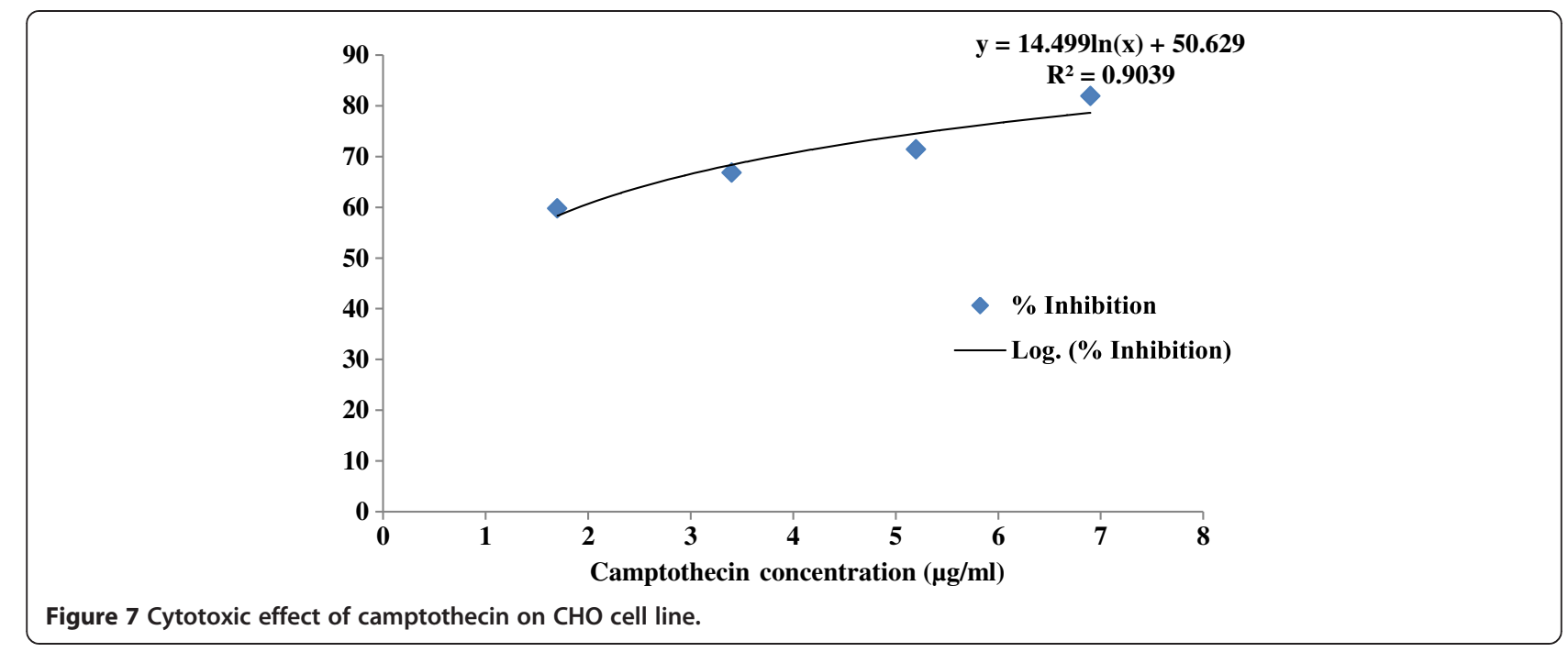

multi-drug-resistant treatments, where lipopeptides are the target compounds of most companies (Mandal et al. 2013). Antimicrobial lipopeptides are nonribosomally synthesized, having macrocyclic peptide cores consisting of eleven to thirteen amino acids, which are rigidified by the formation of a ten-membered ring. They are produced by NRPSs with variation of the fatty acid tail (Strieker and Marahiel 2009). The mechanism of action of lipopeptides is distinct from those of other antibiotics currently on the market. They form pores in membranes of bacteria after oligomerization and these pores may cause transmembrane ion influxes, including $\mathrm{Na}+$ and $\mathrm{K}+$, which result in membrane disruption and cell death. Two key properties of lipopeptides are: i) a number of lipopeptides tend to oligomerize and ii) their ability to interact with membranes via their lipid tail (Straus and Hancock 2006). These unique properties of the lipopeptides prevent pathogens to develop resistance against them, thus makes them highly active against multidrug-resistant bacteria (Mangoni and Shai 2011). Generally the bactericidal activity of the lipopeptide increases, with the addition of a lipid tail of appropriate length (typically $\mathrm{C} 10-\mathrm{C} 12$ ) and lipopeptides containing 14 or 16 carbon atoms in lipid tail length exhibit enhanced antifungal activity in addition to antibacterial activity (Mandal et al. 2013). This can be due to either an increase in the affinity of the lipid tail for the hydrocarbon chains or as a result of the stronger interaction of the cationic peptide with the lipid headgroups (Straus and Hancock 2006).

Antimicrobial lipopeptides have been purified from many bacterial genera including several Streptomyces spp. such as $S$. violaceus var. aspartocinius (aspartocin), S. griseoflavus (tsushimycin), S. viridochromogens (laspartomycin), S. coelicolor (calcium-dependent antibiotic), $S$. roseosporus (daptomycin), S. fradiae (A54145), S. parvulus var. parvuli (parvuline) and S. canus (amphomycin)
(Schneider et al. 2009). The present study reports the production of another novel lipopeptide from a Streptomyces sp. The primary structure of lipopeptide was determined using a combination of chemical reactions and mass spectrometry techniques. It consists of six amino acids linked to aliphatic chain of $-\left(\mathrm{CH}_{2}\right)_{7}-\mathrm{CH}_{2}-\left(\mathrm{CH}_{3}\right)_{2}$ and a long tail of fatty acid chain with six times repeated the molecular mass of $161 \mathrm{Da}$ which is corresponding to $-\mathrm{C}_{12} \mathrm{H}_{19}$. Based on structure and molecular weight $(878.5 \mathrm{Da})$, it is different from already reported lipopeptides viz. daptomycin (1620.6 Da), aspartocin (1317 Da), glumamycin (1290.4 Da), tsushimycin (1304.7 Da) and arylomycin A6 (867.4 Da). Lipopeptides vary in their amino acid and/or fatty acid composition and all these variations in length and branching of the fatty acid chains and amino acid substitutions lead to remarkable lipopeptide diversity and activities. Generally, they are reported to be thermostable, resistant to proteolytic enzymes and inhibit the growth of microorganism by altering the membrane integrity (Mandal et al. 2013). Similarly, lipopeptide in the present study is found to be completely stable for $1 \mathrm{~h}$ at $70^{\circ} \mathrm{C}$, retaining $81.8 \%$ activity even after autoclaving $\left(121^{\circ} \mathrm{C}\right.$ for $\left.15 \mathrm{~min}\right)$. It exhibits absolute activity over a broad $\mathrm{pH}$ range of 5.0 -9.0 and found to be resistant to hydrolytic enzymes: trypsin, proteinase $\mathrm{K}$ and lipase. Similarly, paenibacterin, an antimicrobial lipopeptide produced by Paneibacillus sp. strain is reported to be resistant to trypsin and lipase enzymes (Guo et al. 2012). The strong antibacterial activity of the present lipopeptide can be related to the carbon chain length (C12) of the lipid tail as bactericidal activity of the lipopeptides depends upon the length of the lipid tail. Safety evaluation of the lipopeptide demonstrates its noncytotoxic and non-mutagenic nature which is a prerequisite for development of a drug.

In conclusion, Streptomyces amritsarensis produces a novel antimicrobial lipopeptide that is active against a 
variety of Gram-positive bacteria especially, MRSA. Its stability and non-toxic nature suggest that it may serve as a new pharmacological drug and an addition to the panoply of lipopeptide group of antibiotics. It may also be used in the cosmetics industry for developing skincare products and shampoos as it possesses good surface active property and as emulsifier and bio-preservative in the food industry. Further antimicrobial spectrum of the lipopeptide can be enhanced by chemical modifications in the lipid tail length, increasing number of carbon atoms.

\section{Additional file}

Additional file 1: Figure S1. Ellution profile of the partially purified compound using HPLC reverse phase chromatography on C18 column monitoring by absorbance at $280 \mathrm{~nm}$. Figure S2. Antibacterial activity of lipopeptide against: (a) B. subtilis (b) S. epidermidis (c) M. smegmatis (d) MRSA.

\section{Competing interests}

The author(s) declare that they have no competing interests.

\section{Authors' contributions}

RKM: Conceived the study, designed and performed experiments, critically analyzed data and drafted manuscript. DS: Designed and performed all the experiments, analyzed data and drafted manuscript. SMS: Performed MALDI-TOF-MS and sequencing, elucidated lipopeptide structure and helped to draft manuscript. All authors have read and approved the final manuscript.

\section{Acknowledgement}

The authors are thankful to Department of Science and technology (DST), New Delhi, India for providing the financial support (Project no. SR/WOS-A/ LS-87/2010). We also acknowledge help of Dr. Saroj Arora, Professor, Department of Botanical \& Environmental Sciences, Guru Nanak Dev University, Amritsar help in performing safety evaluation tests.

\section{Author details}

${ }^{1}$ Department of Microbiology, Guru Nanak Dev University, Amritsar, Punjab 143005, India. ${ }^{2}$ Central Research Facility, Indian Institute of Technology, Kharagpur, West Bengal 721302, India.

Received: 19 March 2014 Accepted: 27 May 2014

Published online: 28 June 2014

\section{References}

Baindara P, Mandal SM, Chawla N, Singh PK, Pinnaka AK, Korpole S (2013) Characterization of two antimicrobial peptides produced by a halotolerant Bacillus subtilis strain SK. DU. 4 isolated from a rhizosphere soil sample. AMB Express 3(2):1-11

Bauer AW, Kirby WM, Sherris JC, Turck M (1966) Antibiotic susceptibility testing by a standardized single disk method. Am J Clin Path 45:493-496

Davies J (1999) Millennium bugs. Trends Biochem Sci 24:M2-M5

D'Costa VM, Mukhtar TA, Patel T, Koteva K, Waglechner N, Hughes DW, Wright GD, De Pascale G (2012) Inactivation of the lipopeptide antibiotic daptomycin by hydrolytic mechanisms. Antimicrob Agents Chemother 56(2):757-764

Du Noüy, Pierre L (1925) An Interfacial Tensiometer for Universal Use. J Gen Physiol 7(5):625-633

Guo Y, Huang E, Yuan C, Zhang L, Yousef AE (2012) Isolation of a Paenibacillus sp. strain and structural elucidation of its broad-spectrum lipopeptide antibiotic. Appl Environ Microbiol 78(9):3156-3165

Horn JN, Sengillo JD, Lin D, Romo TD, Grossfield A (2012) Characterization of a potent antimicrobial lipopeptide via coarse-grained molecular dynamics. Biochim Biophys Acta Biomembr 1818(2):212-218
Laverty G, Gorman SP, Gilmore BF (2011) The potential of antimicrobial peptides as biocides. Int J Mol Sci 12:6566-6596

Lowry OH, Rosebrough NJ, Farr AL, Randall RJ (1951) Protein measurement with the Folin phenol reagent. J Biol Chem 193:265-275

Mandal SM, Dey S, Mandal M, Sarkar S, Maria-Neto S, Franco OL (2009) Identification and structural insights of three novel antimicrobial peptides isolated from green coconut water. Peptides 30:633-637

Mandal SM, Barbosa AE, Franco OL (2013) Lipopeptides in microbial infection control: scope and reality for industry. Biotechnol Adv 31(2):338-345

Mangoni ML, Shai Y (2011) Short native antimicrobial peptides and engineered ultrashort lipopeptides: similarities and differences in cell specificities and modes of action. Cell Mol Life Sci 68:2267-2280

Maria-Neto S, Cândido Ede S, Rodrigues DR, de Sousa DA, da Silva EM, de Moraes LM, de Jesus OA, Magalhães BS, Dias SC, Franco OL (2012) Deciphering the magainin resistance process of Escherichia coli strains in light of the cytosolic proteome. Antimicrob Agents Chemother 56(4):1714-1724

Maron DM, Ames BN (1983) Revised method for Salmonella mutagenicity test. Mutat Res 113(3-4):173-215

Nathan C, Goldberg FM (2005) The profit problem in antibiotic R\&D. Nat Rev Drug Discov 4(3):887-891

Payne DJ, Gwynn MN, Holmes DJ, Pompliano DL (2007) Drugs for bad bugs: confronting the challenges of antibacterial discovery. Nat Rev Drug Discov 6:29-40

Pirri G, Giuliani A, Nicoletto S, Pizutto L, Rinaldi A (2009) Lipopeptides as antiinfectives: a practical perspective. Cent Eur J Biol 4(3):258-273

Rice LB (2008) Federal funding for the study of antimicrobial resistance in nosocomial pathogens: no ESKAPE. J Infect Dis 197:1079-1081

Rodriguez de Castro F, Naranjo OR, Marco JA, Violan JS (2009) New antimicrobial molecules and new antibiotic strategies. Semin Respir Crit Care Med 30:161-171

Schneider T, Gries K, Josten M, Wiedemann I, Pelzer S, Labischinski H, Sahl HG (2009) The lipopeptide antibiotic friulimicin B inhibits cell wall biosynthesis through complex formation with bactoprenol phosphate. Antimicrob Agents Chemother 53(4):1610-1618

Sharma D, Mayilraj S, Manhas RK (2014) Streptomyces amritsarensis sp. nov., exhibiting broad-spectrum antimicrobial activity. Antonie Van Leeuwenhoek 105(5):943-949

Skehan P, Storeng R, Scudiero D, Monks A, McMohan J, Vistica D, Warren JT, Bokesch H, Kenney S, Boyd MR (1990) New colorimetric cytotoxic assay for anticancer-drug screening. J Natl Cancer Inst 82:1107-1112

Song J (2008) What's new on the antimicrobial horizon? Int J Antimicrob Agents 32:207-213

Straus SK, Hancock REW (2006) Mode of action of the new antibiotic for Gram-positive pathogens daptomycin: Comparison with cationic antimicrobial peptides and lipopeptides. Biochim Biophys Acta 1758:1215-1223

Strieker M, Marahiel MA (2009) The structural diversity of acidic lipopeptide antibiotics. ChemBioChem 10(4):607-616

Watve MG, Tickoo R, Jog MM, Bhole BD (2001) How many antibiotics are produced by the genus Streptomyces? Arch Microbiol 176(5):386-390

Youssef NH, Dunacn KE, Nagle DP, Savage KN, Knapp RM, Mclnerney MJ (2004) Comparison of methods to detect biosurfactant production by diverse microorganism. J Microbiol Methods 56:339-347

doi:10.1186/s13568-014-0050-y

Cite this article as: Sharma et al.: Purification and characterization of a novel lipopeptide from Streptomyces amritsarensis sp. nov. active against methicillin-resistant Staphylococcus aureus. AMB Express 2014 4:50. 